\title{
Sleeper thistles in New Zealand: status and biocontrol potential
}

\author{
M.G. Cripps ${ }^{1}$, G.W. Bourdôt ${ }^{1}$ and S.V. Fowler ${ }^{2}$ \\ ${ }^{1}$ AgResearch, Lincoln Science Centre, Private Bag 4749, Christchurch, New Zealand \\ ${ }^{2}$ Landcare Research, PO Box 40, Lincoln 7640, New Zealand \\ Corresponding author:mike.cripps@agresearch.co.nz
}

\begin{abstract}
Globally, the thistle tribe, Cardueae (Asteraceae), contains approximately 2,500 species, of which at least 339 have weed status. In New Zealand, 63 of these are present, but only nine are recognised problems, with the remainder being potential threats or "sleeper weeds". To evaluate these potential threats, the 339 global thistle weeds were ranked from most to least important, based on an assigned Index of Weed Importance, and grouped into five weed importance categories: Extreme, High, Moderate, Low and Minor. Of the global species in these categories, $94 \%, 56 \%, 28 \%, 19 \%$ and $7 \%$, respectively, are present in New Zealand, and mitigating the most serious potential threats would be prudent. An option is the novel use of classical biological control agents that specialise on the thistle tribe, rather than specific target species. This is feasible for New Zealand because in the tribe Cardueae there are no natives and few economically-valued exotic species.
\end{abstract}

Keywords Cardueae, thistles, biological control, weed management.

\section{INTRODUCTION}

Thistles are among the worst agriculture weeds in New Zealand (NZ) and throughout temperate regions of the world. Globally, the thistle tribe (Cardueae) is comprised of five subtribes, 73 genera and approximately 2,500 species (Susanna \& Garcia-Jacas 2007), of which 339 species are considered weeds (Randall 2012). The tribe is primarily distributed in the northern hemisphere, with no native representatives in NZ (Webb et al. 1988; Susanna \& Garcia-Jacas 2007). Since European colonisation until the present time, at least 115 species of the thistle tribe have been introduced to NZ, either inadvertently or deliberately, of which 63 species have weed status somewhere in the world. Many of the thistle weeds in NZ were introduced during the early period of European colonisation, probably as contaminants in crop seed (Cockayne 1912). The regional Control of Thistles Acts of 1854 (Wellington) and 1857 (Auckland) are evidence that some of the early thistle introductions quickly became troublesome weeds. These regional Acts were followed by the more comprehensive national Noxious Weeds Act of 1900 that listed all major groups of thistles, curiously also including Carlina, of which no species were known to be present in $\mathrm{NZ}$ at the time. This was likely a precautionary listing of all thistle groups since the introduced flora was not well characterised, but highlights the severity with which thistles were regarded. 
Currently, of the 63 introduced thistle weeds in NZ, nine species are thought to cause economic losses in pastures (Popay et al. 2002; Popay et al. 2010), 11 are included in at least one Regional Pest Management Strategy (RPMS) (of the 15 regional councils in NZ), and none are prohibited from sale or distribution by the National Pest Plant Accord (Ministry for Primary Industries 2013). After accounting for overlap in the economic weeds and those listed in RPMSs, 49 of the 63 thistle weeds remain that are not considered important, and have no legal management requirements. It is worth noting that some of these currently unregulated thistle weeds were previously part of a regional or national management strategy that may have curtailed their invasion. For instance, the former National Noxious Plant Council had an effective control and containment strategy against Grecian thistle (Ptilostemon afer) in Canterbury during the 1980s (Allen \& Harrison 1988), but this weed is no longer part of any RPMS. It is not the intention of this paper to suggest species that should be listed for control by a regulatory body, but rather to highlight that there is a large group of known thistle weeds that are currently not considered problematic in NZ.

Identifying potential weeds is of strategic importance to help ensure the future productivity and sustainability of NZ agroecosystems. This large pool of presently unimportant thistle weeds could be regarded as "sleeper weeds", species with potential to become serious weeds (Groves 2006). Other than the fact that these species are known weeds elsewhere in the world, which is a good predictor of invasion success (Reichard 2001), little is understood about their potential to become invasive in NZ. This is in part because most research has focused on the three most important thistle weeds: Cirsium arvense, Cirsium vulgare and Carduus nutans, with very little, or no research on the other thistle species. Likewise, the biological control effort has focused only on these three species.

The aim of this study was to examine the global weed species of the thistle tribe and compare these against the species known to be present in NZ as an initial assessment of the future risks from the global pool, and the present naturalised species.

\section{MATERIALS AND METHODS}

Following the classification of Susanna \& GarciaJacas (2007), each of the recognised Cardueae genera were searched for in the second edition of the Global Compendium of Weeds (Randall 2012). Each Cardueae weed species listed was recorded along with the number of references in Randall (2012) indicating the species is a weed, and the weed statuses assigned to it by Randall (2012). Subspecies and varieties listed as weeds were not recorded. The 14 possible weed statuses were subjectively evaluated based on the description provided and were each assigned a score from 1 to 10 (casual alien $=1$; native weed $=1$; unconfirmed naturalisation $=1$; weed $=2$; cultivation escape $=4$; garden escape $=4$; naturalised $=4$; sleeper weed $=4$; agricultural weed $=5$; environmental weed $=5$; containment $=6$; $\quad$ invasive $=8$; $\quad$ noxious $=10$; quarantine $=10)$. An Index of Weed Importance (IWI) was calculated by summation of the number of references plus the status score. The IWI was used to categorise the weeds into five importance groups: Extreme $\geq 100$; High $=50$ to 99; Moderate $=20$ to 49 ; Low $=10$ to 19 ; Minor $<10$. The thistle weeds were further categorised taxonomically based on informal groupings of the related genera ( 1 to 9 genera per group) provided by Susanna \& Garcia-Jacas (2007). Based on the IWI value, the listed weeds were ranked from most (highest index value) to least (lowest index value) important. Species with the same IWI value were assigned the same rank number. The presence or absence of each species in NZ was determined by checking the Cardueae component of the introduced plants database compiled by Duncan \& Williams (2002) (available upon request from the authors). The median importance ranking of the present versus absent thistle weeds in NZ was analysed using the nonparametric MannWhitney test. The equality of variances in the rankings of the present versus absent thistle weeds was compared using Levene's test since it is less sensitive to non-normally distributed 
data than other similar test statistics. All analyses were performed in Minitab version 15.

\section{RESULTS}

The number of thistle weeds globally and present in NZ are listed according to their taxonomic groups and importance ranking (Table 1). Weeds of extreme and high importance are represented by only six of the 16 taxonomic groups containing thistle weeds. The 18 species of extreme importance are listed in Table 2, of which all are present in NZ except Centaurea diffusa. Comparison of the median rank of thistle weeds present (median $=45$ ) versus absent (median $=68$ ) in NZ showed that the present species were significantly more important weeds than the absent species (Figure 1; $\mathrm{P}<0.001$ ). Similarly, the variation in the importance rankings of the present species (standard deviation $=24.8$ ) was significantly greater than the absent species ( standard deviation $=10.6)(\mathrm{P}<0.001)$ indicating a wider range in the importance of introduced thistle weeds (Figure 1). The lower variation in the importance rankings of the absent thistle weeds is due to the majority of species in this group being of minor importance (Figure 1; Table 1).

\section{DISCUSSION}

This global examination of the Cardueae weeds clearly shows that the most important thistle weeds are already present in NZ. While some

Table 1 Number of Cardueae weed species globally, classified into five importance categories (based on their assigned Index of Weed Importance) and by informal taxonomic groups. Taxonomic groups without weeds are not listed. The number present in New Zealand is indicated in parentheses.

\begin{tabular}{|c|c|c|c|c|c|c|}
\hline \multicolumn{2}{|c|}{ Taxonomic group } & \multicolumn{5}{|c|}{ Weed Importance Category } \\
\hline Subtribe & Informal group & Extreme & High & Moderate & Low & Minor \\
\hline \multicolumn{7}{|c|}{ Carduinae } \\
\hline & Arctium & $2(2)$ & 1 & -- & 2 & 7 \\
\hline & Carduus & $7(7)$ & $4(2)$ & $13(4)$ & $22(6)$ & $69(2)$ \\
\hline & Onopordum & $1(1)$ & $3(2)$ & $1(1)$ & 3 & 11 \\
\hline & Saussurea & -- & -- & 2 & 1 & $11(4)$ \\
\hline & Xeranthemum & -- & -- & -- & $2(1)$ & 3 \\
\hline & Unplaced & -- & -- & -- & -- & 1 \\
\hline \multicolumn{7}{|c|}{ Carlininae } \\
\hline & Atractylis & -- & -- & -- & 1 & 5 \\
\hline & Atractylodes & -- & -- & -- & 1 & $1(1)$ \\
\hline & Carlina & -- & -- & -- & $4(1)$ & 5 \\
\hline \multicolumn{7}{|c|}{ Centaurinae } \\
\hline & Carthamus & $1(1)$ & $1(1)$ & 5 & 2 & 4 \\
\hline & Centaurea & $7(6)$ & $6(3)$ & $16(4)$ & $13(1)$ & $69(8)$ \\
\hline & Rhaponticum & -- & -- & -- & -- & 1 \\
\hline & Serratula & -- & -- & -- & $2(1)$ & 5 \\
\hline & Volutaria & -- & -- & 1 & 1 & 4 \\
\hline & Unplaced & -- & -- & -- & -- & 4 \\
\hline \multicolumn{7}{|c|}{ Echinopsinae } \\
\hline & Echinops & -- & $1(1)$ & $2(2)$ & $4(1)$ & 7 \\
\hline Total spe & & 18 & 16 & 40 & 58 & 207 \\
\hline Present ir & & 94.4 & 56.3 & 27.5 & 19.0 & 7.2 \\
\hline
\end{tabular}


Table 2 The global Cardueae weeds of "Extreme" importance ranked by their Index of Weed Importance (IWI) score (IWI score $=$ Status score + Reference score).

\begin{tabular}{|c|c|c|c|}
\hline Species & Status score & Reference score & IWI score \\
\hline Cirsium arvense $e^{1}$ & 55 & 205 & 260 \\
\hline Cirsium vulgare ${ }^{1}$ & 55 & 176 & 231 \\
\hline Silybum marianum ${ }^{1}$ & 56 & 149 & 205 \\
\hline Carduus nutans ${ }^{1}$ & 58 & 128 & 186 \\
\hline Centaurea solstitialis & 51 & 114 & 165 \\
\hline Onopordum acanthium & 55 & 109 & 164 \\
\hline Centaurea melitensis & 55 & 104 & 159 \\
\hline Centaurea calcitrapa & 55 & 97 & 152 \\
\hline Carthamus lanatus & 54 & 96 & 150 \\
\hline Centaurea cyanus & 36 & 110 & 146 \\
\hline Arctium minus $^{1}$ & 55 & 85 & 140 \\
\hline Carduus acanthoides ${ }^{1}$ & 51 & 89 & 140 \\
\hline Cynara cardunculus & 55 & 76 & 131 \\
\hline Centaurea (Acroptilon) repens & 51 & 79 & 130 \\
\hline Carduus pycnocephalus ${ }^{1}$ & 41 & 88 & 129 \\
\hline Centaurea diffusa ${ }^{2}$ & 51 & 75 & 126 \\
\hline Centaurea maculosa & 55 & 53 & 108 \\
\hline Arctium lappa & 45 & 57 & 102 \\
\hline
\end{tabular}

${ }^{1}$ Species of economic significance in NZ. Although not of "Extreme" global importance, Cirsium palustre and Carduus tenuiflorus are also of economic significance in NZ, and ranked with "High" global importance.

${ }^{2}$ Species not known to be present in NZ.

important thistle weeds not present in NZ exist in the global pool, there have been very few new introductions of agricultural weeds since the 1950s, possibly due to NZs stringent biosecurity regulations (Williams et al. 2010). On the basis that weed status elsewhere is a good predictor of invasion success, border biosecurity might be less critical than internal management for thistle weeds. The top four global thistle weeds correspond reasonably well with the worst thistle weeds in NZ, although at present nodding thistle (Carduus nutans) would be considered a much worse weed than variegated thistle (Silybum marianum). Other thistle weeds of economic significance in NZ would also rank with either extreme or high importance globally, conferring with the prediction that weed status elsewhere is a good indicator of invasion success. However, another 10 species ranked as extreme weeds globally are present in NZ, but not considered serious problems in NZ. The reason these other weeds of extreme global importance are not problematic in NZ is unclear, and highlights the need to better understand weed invasions. The fifth most important weed globally, yellow starthistle (Centaurea solstitialis) is one of the worst weeds in western North America (NA), infesting over 6 million hectares in California alone. The success of this weed is attributed to its ability to thrive in temperate climates with 250 to $1500 \mathrm{~mm}$ annual rainfall, and occupy a wide variety of habitats (DiTomaso et al. 2006). In NZ, Cheeseman (1882) reported yellow starthistle to be "spreading fast, especially in the Waikato". This weed may have been spreading fast at that time, but it never became widespread or abundant, possibly due to changes in farm management practices, and early weed control 


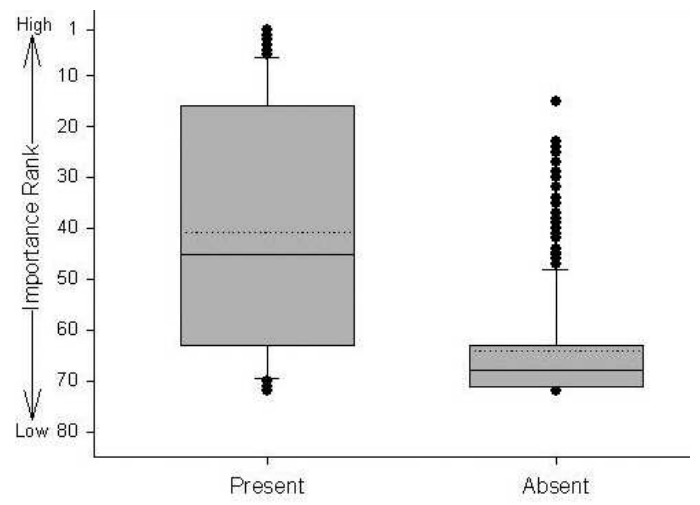

Figure 1 Box and whiskers plots depicting the distribution of the importance rankings of Cardueae weeds present in New Zealand and absent from New Zealand. The boxes delimit the interquartile ranges, with the solid line representing the median and the dotted line the mean. The ends of the whiskers represent the $90^{\text {th }}$ and $10^{\text {th }}$ percentiles, and the dots represent species with rankings above or below these points, respectively.

legislation that may have curbed the invasion of this and other thistle species (Popay et al. 2002; Williams et al. 2010).

It is possible that some of these introduced thistles are sleeper weeds that could become serious weed problems given the right conditions. When considering which sleeper weeds might become problematic, the rankings assigned to these weed species must be treated with some caution, especially for the low and minor ranked species. The database of Randall (2012) is compiled from 1285 global sources that over-represent some regions, particularly Australia and NA. The important weeds in the over-represented regions will be identified, but possibly some important weeds in under-represented regions where there is less investment in weed research could be assigned a score that does not adequately represent their importance.

Conceivably, both the current and sleeper thistle weeds could be managed through a novel approach to classical biological control. Thistles belong to a well defined taxonomic group, of which there are no native representatives in NZ, offering a unique opportunity for biological control of the Cardueae tribe. To date, 10 biocontrol agents have been released in NZ for control of the three most important thistle weeds: Cirsium arvense, Cirsium vulgare and Carduus nutans. From 1973 to 1998, eight of these biocontrol agents were released. During this period, the biocontrol programme in NZ made use of 'transfer projects', whereby the same agents released in USA and Canada were subsequently released in NZ (Fowler et al. 2010). The agents selected for release in USA and Canada were the most host-specific options due to the large number of native thistles occurring there. The use of transfer projects was an economical way to safely release biocontrol agents, but not the best approach for releasing the most effective agents for NZ (Cripps et al. 2011). More recently, a new approach, considering the absence of native Cardueae in NZ, has resulted in the release of Cassida rubiginosa in 2007 and Certapion onopordi in 2009. The host range of these agents is much broader than any of the previously released agents and includes many species in the Cardueae tribe. The potential for these agents to impact multiple thistle weeds has been recognised (Bourdôt et al. 2007), but the primary aim has been the biocontrol of a single target species, C. arvense. Future biological control considerations might benefit from a broader-target perspective, and seek agents that would best control the tribe, rather than currently important thistle species. This broader perspective would open up a greater source area for potential biocontrol agents and thereby increase the number of options and the chances of success. Previously, all biocontrol agents were sourced from Europe, the native range of the target species and the area of greatest diversification of thistle herbivores. However, secondary centres of Cardueae diversification such as NA and eastern Asia, with their own suite of specialist herbivores, could be considered as sources of biocontrol agents. Of course, any investigation into additional 
biocontrol agents must also consider potential impacts on Cardueae plants of value, such as artichoke, safflower and species with beneficial medicinal properties (Barratt et al. 2010).

In conclusion, the next major thistle weed is most likely to arise from the pool of already introduced species. Mitigating this threat would be prudent. A tribal level approach to classical biological control would have potential to control current thistle weeds and also safe-guard against sleeper thistles.

\section{ACKNOWLEDGEMENTS}

The study was supported by funding from the Ministry of Business, Innovation and Employment through the Undermining Weeds programme. We thank two anonymous reviewers for helpful comments, and Chikako van Koten for statistical advice.

\section{REFERENCES}

Allen FC, Harrison RA 1988. Grecian thistle phenology and control. Proceedings of the 41st New Zealand Weed and Pest Control Conference 70-74.

Barratt BIP, Howarth FG, Withers TM, Kean JM, Ridley GS 2010. Progress in risk assessment for classical biological control. Biological Control 52: 245-254.

Bourdôt GW, Fowler SV, Edwards GR, Kriticos DJ, Kean JM, Rahman A, Parsons AJ 2007. Pastoral weeds in New Zealand: status and potential solutions. New Zealand Journal of Agricultural Research 50: 139-161.

Cheeseman TF 1882. The naturalised plants of the Auckland provincial district. Transactions of the New Zealand Institute 15: 268-298.

Cockayne AH 1912. Impure seed: the source of our weed problem. Journal of the Department of Agriculture 4: 437-443.

Cripps MG, Gassmann A, Fowler SV, Bourdot GW, McClay AS, Edwards GR 2011. Classical biological control of Cirsium arvense: Lessons from the past. Biological Control 57: 165-174.

DiTomaso JM, Kyser GB, Pitcairn MJ 2006. Yellow starthistle management guide. California Invasive Plant Council, Berkeley, CA. 78 p.
Duncan RP, Williams PA 2002. Darwin's naturalization hypothesis challenged. Nature 417: 608-609.

Fowler SV, Paynter Q, Hayes L, Dodd S, Groeteman R 2010. Biocontrol of weeds in New Zealand: an overview of nearly 85 years. In: Zydenbos SM ed. Seventeenth Australasian Weeds Conference. New Zealand Plant Protection Society, Chirstchurch, New Zealand. Pp. 211-214.

Groves RH 2006. Are some weeds sleeping? Some concepts and reasons. Euphytica 148: 111-120.

Ministry for Primary Industries 2013. National Plant Pest Accord. http://www.biosecurity. govt.nz/nppa (accessed 31 March 2013).

Popay AI, Rahman A, James TK 2002. Future changes in New Zealand hill country pasture weeds. New Zealand Plant Protection 55: 99105.

Popay I, Champion P, James T 2010. An illustrated guide to common weeds of New Zealand. New Zealand Plant Protection Society, Christchurch, New Zealand. 416 p.

Randall RP 2012. A Global Compendium of Weeds. Department of Agriculture and Food, Perth, Western Australia. 1119 p.

Reichard S 2001. The search for patterns that enable prediction of invasion. In: Groves RH, Panetta FD, Virtue JG ed. Weed risk assessment. CSIRO, Collingwood, Australia. Pp. 10-19.

Susanna A, Garcia-Jacas N 2007. Tribe Cardueae Cass. (1819). In: Kubitzki K ed. The families and genera of vascular plants. SpringerVerlag, Berlin. Pp. 123-147.

Webb CJ, Sykes WR, Garnock-Jones PJ 1988. Flora of New Zealand. DSIR, Botany Division, Christchurch, New Zealand. 1365 p.

Williams PA, Popay I, Gatehouse HAW 2010. New Zealand biosecurity legislation and the naturalization of exotic weeds. Plant Protection Quarterly 25: 95-98. 